NASA Technical Memorandum 88980

\title{
Microwave Performance of an Optically Controlled AlGaAs/GaAs High Electron Mobility Transistor and GaAs MESFET
}

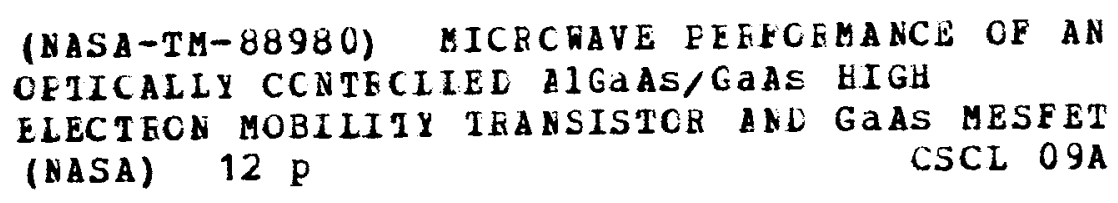

N87-17993

Unclas G3/33 43529

Rainee N. Simons and Kul B. Bhasin

Lewis Research Center

Cleveland, Ohio

Prepared for the

1987 IEEE MTT-S International Microwave Symposium and Exhibition

Las Vegas, Nevada, June 9-11, 1987 


\title{
MICROWAVE PERFORMANCE OF AN OPTICALLY CONTROLLED AIGaAs/GaAs HIGH ELECTRON MOBILITY TRANSISTOR AND GaAs MESFET
}

Rainee N. Simons* and Kul B. Bhas in

\author{
National Aeronautics and Space Administration \\ Lewis Research Center \\ Cleveland, Ohio 44135
}

\begin{abstract}
Direct current and also the microwave characteristics of optically illuminated AlGaAs/GaAs HEMT are experimentally measured for the first time and compared with that of GaAs MESFET. The results showed that the average increase in the gain is $2.8 \mathrm{~dB}$ under $1.7 \mathrm{~mW} / \mathrm{cm}^{2}$ optical intensity at $0.83 \mu \mathrm{m}$. Further, the effect of illumination on $S$-parameters is more pronounced when the devices are biased close to pinch-off. Novel applications of optically illuminated HEMT as a variable gain amplifier, high-speed highfrequency photo detector, and mixer are demonstrated.
\end{abstract}

\section{Introduction}

Use of direct optical control of microwave semiconductor devices for optical injection locking, phase shifting, and sigral distribution has the potential to enhance the performance of future space borne phased array antenna systems. 1,2 Previously, several authors have experimentally investigated the effect of light on the dc as well as the microwave characteristics of IMPATT diodes and GaAs MESFETs. 3-6 Their investigations show that these changes in the characteristics are due to photoconductivity and photovoltaic effects. Further, an analytical study, by the authors taking into consideration material properties of hetrostructures showed that the hetrostructures have a higher sensitivity to optical illumination. When this investigation was extended to microwave device structures, it was observed that the dc characteristics of an AlGaAs/GaAs High Electron Mobility Transistor (HEMT), when compared to that of a GaAs MESFET, are more sensitive to optical illumination greater than the semiconductor band gap. ${ }^{7}$

In this paper, we present for the first time extensive experimental results which show the sensitivity to optical illumination, that is, the light induced voltage and as a consequence the changes in the drain to source current, the intrinsic transconductance, the scattering parameters,

*National Research Council - NASA Research Associate. and the gain of an ATGaAs/GaAs HEMT. Further, fromthe de-embedded HEMT scattering parameters, the changes in the equivalent circuit element values due to optical illumination are also computed. In order, to compare and contrast the performance of a HEMT with a MESFET, experiments are also carried out on two different GaAs MESFETs and these results are also presented here. Finally, three novel applications of optically illuminated HEMT as a variable gain amplifier, high-speed high-frequency photo detector, and mixer are demonstrated.

\section{Experimental Setup}

A low noise AlGaAs/GaAs High Electron Mobility Transistor (MPO-H503, Gould Inc.) with recessed $P_{i-g a t e}$ of length $0.5 \mu \mathrm{m}$ and width $280 \mu \mathrm{m}, 8 \mathrm{a}$ low noise, low power GaAs MESFET (DXL 0503A, Gould Inc.) with recessed $\mathrm{Pi}$-gate of length $0.3 \mu \mathrm{m}$ and width $280 \mu \mathrm{m}$, and a medium power GaAs MESFET (RPX 2322, Raytheon Co.) with T-gate of length of $0.5 \mathrm{um}$ and width $500 \mu \mathrm{m}$ are used for investigation. For optical illumination an AlGaAs/GaAs Laser diode (SL-620 S, Ortel Corp.) with a fiber pigtail, which operates at a wavelength of $0.83 \mathrm{um}$ and has a direct modulation bandwidth of $6 \mathrm{GHz}$ is used. The optical power emitted from the $50 \mu \mathrm{m}$ multimode graded index optical fiber pigtail as measured using a calibrated digital power meter and a photosensor (815, Newport Corp.) is $1.7 \mathrm{~mW} / \mathrm{cm}^{2}$. The tip of the fiber is held at a distance of $1 \mathrm{~mm}$ from the device.

These devices are mounted on a 0.375 by 0.375 in., 25 mil thick alumina carrier. The alumina carrier also accommodates a pair of $50 \Omega$ coplanar waveguides (CPW) which serve as the signal input and also output ports. The device gate and drain pads and the source pad are wire bonded to the CPW center strip conductors and the ground plane respectively. The carrier is then mounted in a test fixture (Design Techniques, Inc.) which has two $3.5 \mathrm{~mm}$ coaxial connectors for external connection. The test fixture also has provision for ensuring repeatable pressure contact between the terminals of the CPWs on the carrier and the two $3.5 \mathrm{~mm}$ coaxial connectors on the fixture. A CPW calibration kit consisting of a $50 \Omega$ through, two short circuits, and an open circuit on similar alumina carriers are used for calibrating the HP8510 automatic network analyzer and de-embedding 
the device S-parameters. A block schematic of the entire experimental setup is shown in Fig. 1 .

\section{dc Device Characteristics Under Illumination}

\section{Light Induced Voltage}

The light generated voltage $v_{\text {lit }}$ is obtained by plotting the measured gate current $I_{g}$ as a function of the reverse biased gate to source voltage $V_{g s}$, and extrapolating the graph till it intersects the $X$-axis. The intersection point is read as the light generated voltage, which from Fig. 2(a) and (b) for a AlGaAs/GaAs HEMT and a GaAs MESFET are 0.57 and $0.24 \mathrm{~V}$ respectively.

Drain to Source Current, Transconductance, and Gain

The measured drain to source current $I_{d s}$ as a function of the drain to source voltage $v_{d s}$ with and without optical illumination for an AlGaAs/GaAs HEMT and a GaAs MESFET are presented in Fig. 3(a) and (b) respectively.

Figure 4 presents the measured dc transconductance $g_{m}$ for a GaAs MESFET. The $g_{m}$ is considered almost insensitive to optical illumination since the maximum change observed is less than 2 mmhos.

The measured gain with and without optical illumination as a function of $V_{g s}$ for an AIGaAs/GaAs HEMT and a GaAs MESFET are presented in Fig. 5(a) and (b) respectively. As an example, for the case of a AIGaAs/GaAs HEMT, the gain increases by $2.5 \mathrm{~dB}$ at $\mathrm{V}_{\mathrm{gs}}=-0.95 \mathrm{~V}$ and frequency equal to $26.5 \mathrm{GHz}$ when the illumination is $1.7 \mathrm{~mW} / \mathrm{cm}^{2}$.

\section{Microwave Characteristics Under Illumination}

The S-parameters, namely $S_{11}, S_{22}$, and $S_{12}$ are measured as a function of the frequency and illumination $\left(1.7 \mathrm{~mW} / \mathrm{cm}^{2}\right)$ with the devices biased close to saturation and also pinch-off. These bias points or operating points are labeled as points $A$ and $B$ respectively in Fig. 5(a) for the AlGaAs/GaAs HEMT and Fig. 5(b) for the GaAs MESFET.

The measured $S_{11}$ over the frequency range 0.045 to $26.5 \mathrm{GHz}$ for AlGaAs/GaAs HEMT in pinchoff ( $\left.V_{\mathrm{gs}}=-0.95 \mathrm{~V}\right)$ condition is illustrated on a Smith Chart plot in Fig. 6(a). Similarly, S22 is illustrated in Fig. 6(b). Figure 6(c) illustrates $\mathrm{S}_{12}$ on a linear magnitude polar plot. In these figures $L$ and $D$ denotes that the measurements are carried out with or without illumination. A similar set of measurements have also been carried out for GaAs MESFET.

Thus from Fig. 6 it is observed that illumination does affect $S_{11}, S_{22}$, and $S_{12}$. Besides, this effect is more pronounced when the devices are biased close to pinch-off.

Using the CPW calibration kit and the through, short, delay (TSD) technique the influence of the small length of coplanar waveguide on either sides of the chip devices and the test fixture coaxial connectors are effectively removed. The small signal device equivalent circuit element values are next obtained from the de-embeddded device $S$-parameters using the models in Refs. 9 and 10. As an example, $\mathrm{Fig} .7$ shows an increase in the gate and the source capacitances and a decrease in the gate to drain feedback capacitance, with optical illumination. In addition, the model also shows that the gate charging resistance $R_{1}$ and the channel resistance $R_{0}$ both decrease with optical illumination. The effect of these on the $f_{t}, f_{\max }$, and noise figure are being further investigated.

\section{Optically Controlled HEMT as a Variable Gain Amplifier}

The feasibility of using an AlGaAs/GaAs HEMT as an optically controlled variable gain amplifier is clearly evident from the measured $S_{21}$ magnitude and phase characteristics shown in Figs. 8(a) to (d). Figure $8(a)$ and (b) when compared, show that the gain increases with illumination. Further it is interesting to observe that the phase of $S_{21}$ is insensitive to optical illumination as evident from Figs. $8(\mathrm{c})$ and (d).

\section{High Frequency HEMT Photodetector}

An experiment was conducted by illuminating the HEMT device with an optical signal which had been modulated with a $6 \mathrm{GHz}$ RF signal and observing the output on a spectrum analyzer, which is shown in Fig. $9(\mathrm{a})$.

\section{HEMT Oscillator and HEMT Mixer with Optically Coupled Lo}

The capacitance variation of HEMT with illumination is shown in Fig. 7. This can be successfully exploited in the design of an injection locked oscillator.

Preliminary experiments with a HEMT as a mixer show that it is possible to optically couple the local oscillator signal. This is achieved by directly modulating a laser diode at the local oscillator frequency $(6 \mathrm{GHz})$. The laser diode output is then made to illuminate the gate region of the HEMT. The RF signal $(9 \mathrm{GHz})$ is electrically coupled to the aate terminal. The resulting If signal ( $3 \mathrm{GHz}$ ) as seen on a spectrum analyzer is shown in $\mathrm{Fig}$. $9(\mathrm{~b})$.

\section{Conclusions}

The paper presents for the first time extensive experimental results which show the sensitivity to optical illumination. The light induced voltage and as a consequence the changes in, the drain to source current, the intrinsic transconductance, the scattering parameters, and the gain of an AIGaAs/GaAs HEMT have been measured. The light induced voltage for a HEMT is observed to be $0.57 \mathrm{~V}$ and $0.24 \mathrm{~V}$ for MESFET at $0.83 \mu \mathrm{m}$ wavelength. The higher $V_{l i t}$ for HEMT is attributed to the higher increase in hole concentration $\Delta p$ mainly due to the absorption thickness d, (see Eq. 1). Further, from the de-embeddded HEMT scattering 
parameters the changes in the equivalent circuit element values due to optical illumination are also computed. These computations show an increase in the gate and also the drain capacitances and a decrease in the gate charging and also the channel resistances. The effect of these changes on the $f_{t}, f_{\max }$ and the noise figure is being further investigated. In addition to the above, experimental results or GaAs MESFETs have also been presented for comparison.

In these experiments the HEMT is optically illuminated by an AlGaAs/GaAs laser diode. This feature further enhances the attractiveness of the above experiments, since it leads to the possibility of integrating a HEMT and a laser diode on a single MMIC chip to perform multiple circuit functions optically, such as, switching, amplifier gain control, phase shifting, and mixing. Such an integration, when fully accomplished not only promises improved MMIC circuit performance, but also vastly simplifies the signal distribution and beam steering in future phased array antenna.

Finally, three novel applications of an optically illuminated HEMT as a variable gain amplifier, high frequency photo detector, and mixer are demonstrated.

\section{Acknow ledgment}

The authors wish to acknowledge Robert Romanofsky of NASA Lewis Research Center and Vladimir Sokolov of Honeywell Physical Sciences Center for assistance in bonding the MESFETs and HEMTs used in the experiments.

\section{References}

1. R.G. Hunsperger, "Optica? control of Microwave Devices," in Integrated Optical Circuit Engineering II, SPIE vol. 578, S. Sriram, Ed., Bellingham: SPIE, 1985, pp. 40-45.
2. J. Austin and J.R. Forrest, "Design Concepts for Active Phased-Array Modules," IEEE Proc., Part F; Communications, Radar and Signal Processing. vol. 127, pp. 290-300, 1980.

3. A.A.A. DeSalles, "Optical Control of GaAs MESFET's," IEEE Trans. Microwave Theory Tech., vo1. MTT-31, pp. 812-820, 1983

4. J.L. Gautier, D. Pasquet, and P. Pouvil, "Optical Effects on the Static and Dynamic Characteristics of a GaAs MESFET," IEEE Trans. Microwave Theory Tech., vol. MTT-33, pp. 819-822, 1985.

5. H. Mizuno, "Microwave Characteristics of an Optically Controlled GaAs MESFET," IEEE Trans. Microwave Theory Tech., vol. MTT-31, pp. 596-600, 1983

6. W. Chen, N.E. Byer, M.P. Bendett, and R.G. Hunsperger, "Optical Control of IMPATT Diodes," in Optical Technology for Microwave Applications, SPIE vol. 477, S.-K. Yao, Ed., Bellingham:SPIE, 1984 , pp. 105-108.

7. R.N. Simons and K.B. Bhasin, "Analys is of Optically Controlled Microwave/Millimeter Wave Device Structures," IEEE Trans. Microwave Theory Tech., vol. MTT-34, pp. 1349-1355, 1986.

8. A. Swanson, J. Herb, and M. Yung, "First Commercial HEMT Chailenges GaAs FETs," Microwaves \& RF, vol. 24, no. 12, pp. 107-118, 1985.

9. R.A. Minasian, "Simplified GaAs MESFET model to $10 \mathrm{GHz}$," Electron. Lett., vol. 13, pp. 549-551, 1977.

10. Touchstone User Manual, Version 1-4, EEsof Inc., pp. EL-15 to 18, June 1986. 


\section{Cu \\ OF FOSR QUALITY}

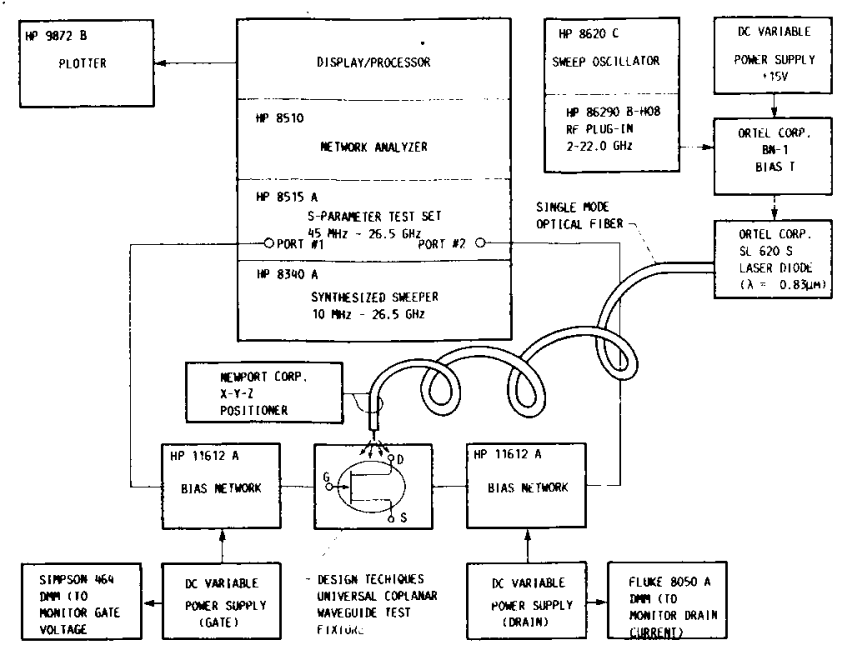

FIGURE 1. - BLOCK SCHEMATIC OF THE EXPERIMENTAL SETUP.

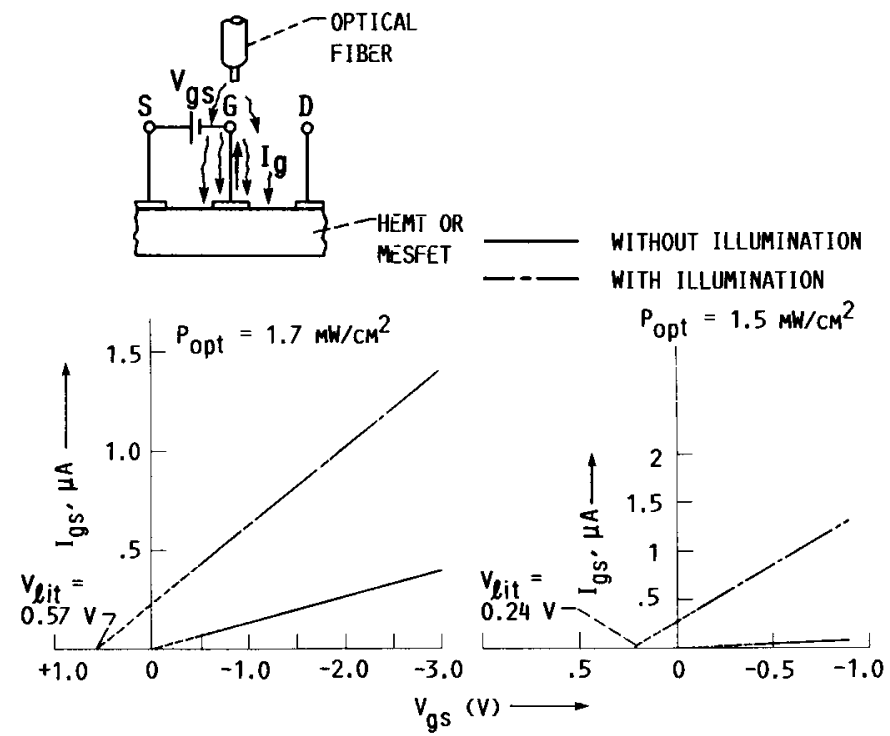

(A) DEVICE ALGAAS/GAAS HEMT (MODEL NO. MPD-H503);

$\mathrm{v}_{\mathrm{ds}}=0 \mathrm{~V}$.

FIGURE 2. - MEASURED $I_{g}$ VERSUS $V_{d S}$ FROM WHICH $V_{\ell \text { IIT }}$ IS OBTAINED. DISTANCE BETHEEN END OF FIBER AND DEVICE, $1 \mathrm{mM}: \lambda=0.83 \mu \mathrm{m}$; $P_{\text {opt }}=1.5 \mathrm{mH} / \mathrm{cm}^{2}$.
(B) DEVICE GAAS MESFET (MODEL No. $\operatorname{RPX} 2322): V_{d s}=0 \mathrm{~V}$. 


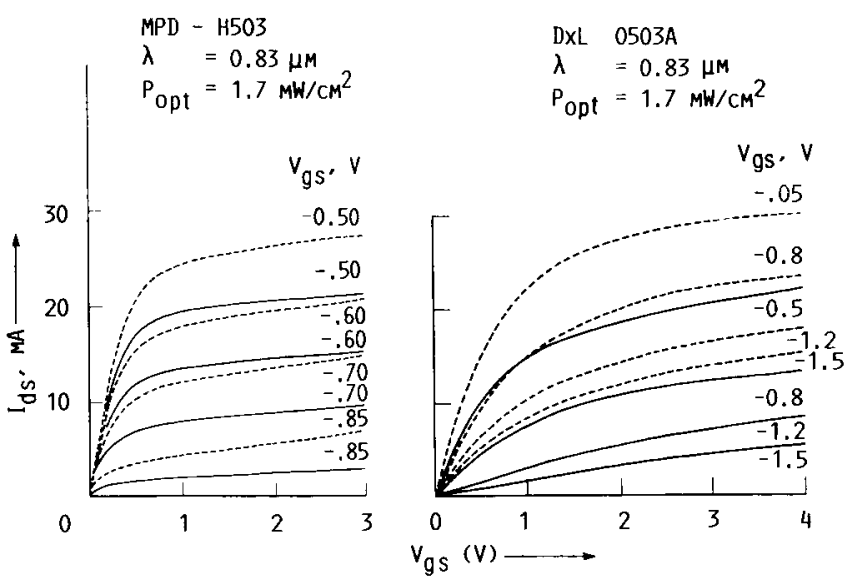

FIGURE 3. - MEASURED $I_{d S}$ VERSUS $V_{d s}$ WITH AND WITHOUT OPTICAL ILLUMINATION.

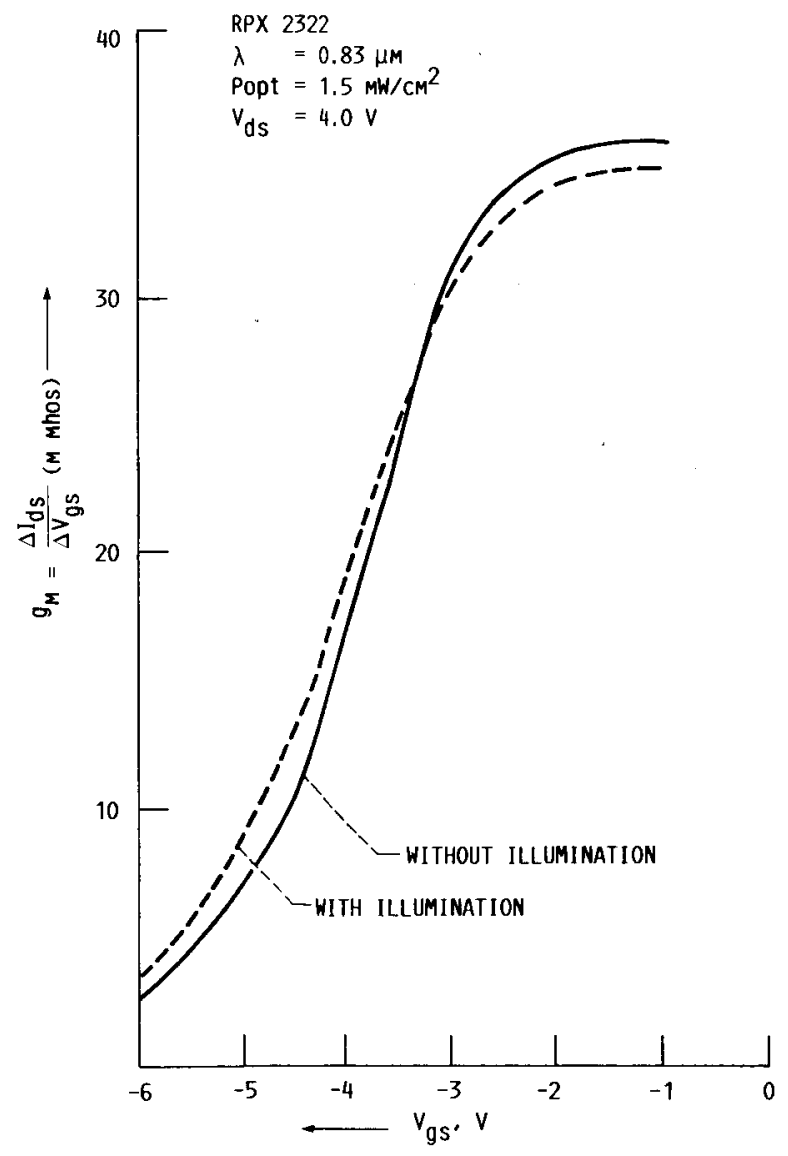

FIGURE 4. - MEASURED $g_{M}$ VERSUS $V_{\text {OS }}$ FOR GAAS MESFET WITH AND WITHOUT OPTICAL ILLUMINATION. 


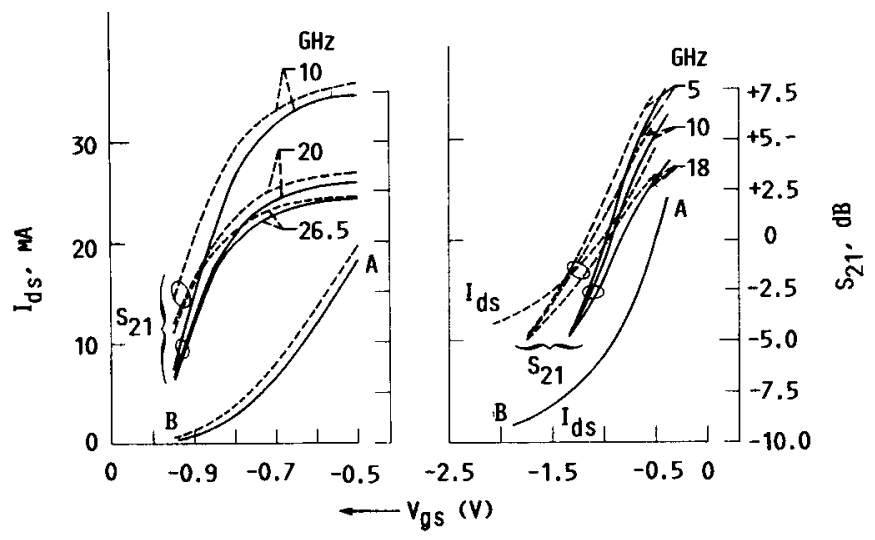

(A) DEVICE ALGAAS/GAAS HEMT (B) DEVICE, GAAS MESFET (MODEL NO. (MODEL. NO. MPD-H503); $v_{d s}=3.0 \mathrm{~V}$.

NO. DxL. $0503 \mathrm{~A}) ; V_{d \mathrm{ds}}=3.5 \mathrm{~V}$.

FIGURE 5. - MEASURED GAIN VERSUS VgS WITH AND HITHOUT ILLUMINATION. DISTANCE BETWEEN END OF FIBER AND DEVICE, $1 \mathrm{MM} ; \lambda=0.83 \mu \mathrm{M}: \mathrm{P}_{\text {Opt }}=1.7 \mathrm{~mW} / \mathrm{cm}^{2}$. 


\section{ORIEHFA
OF POOR QUALTY}
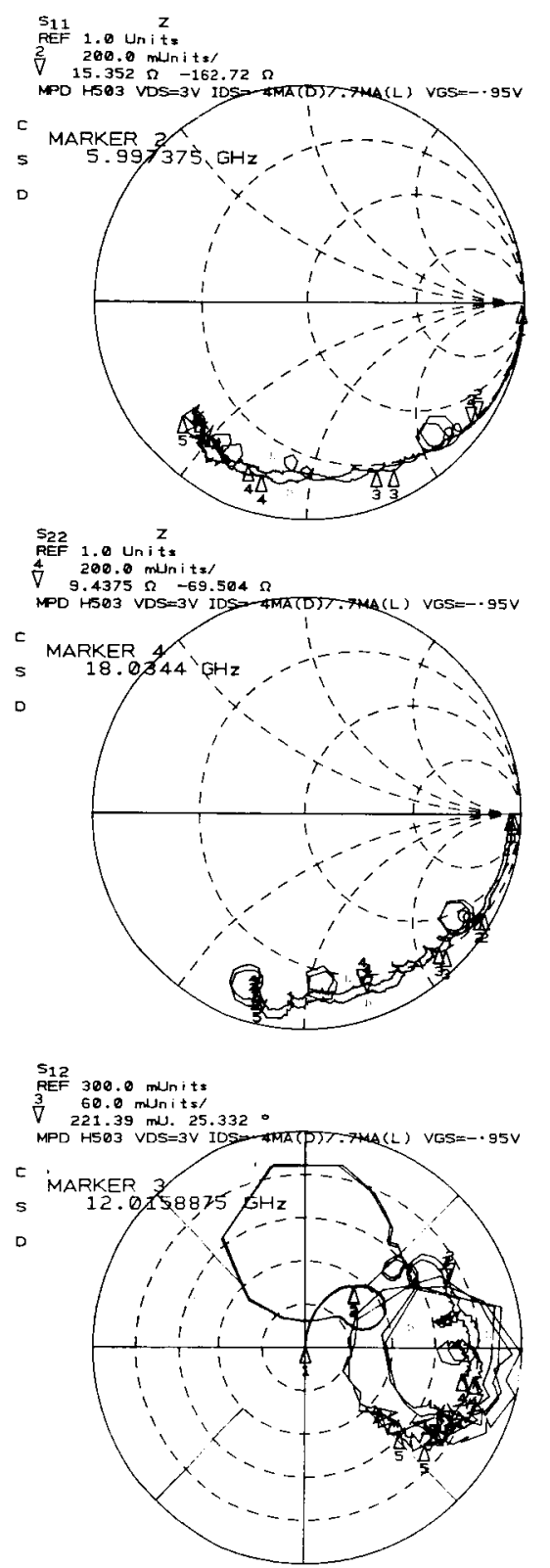

FIgURE 6. - MEASURED S-PARAMETERS FOR AlgaAs/ GAAS HEMT WITH AND WITHOUT ILLUMINATION WHEN BIASED CLOSE TO PINCH-OFF. START $0.045 \mathrm{GHz}$, STOP $26.5 \mathrm{GHz}$. 


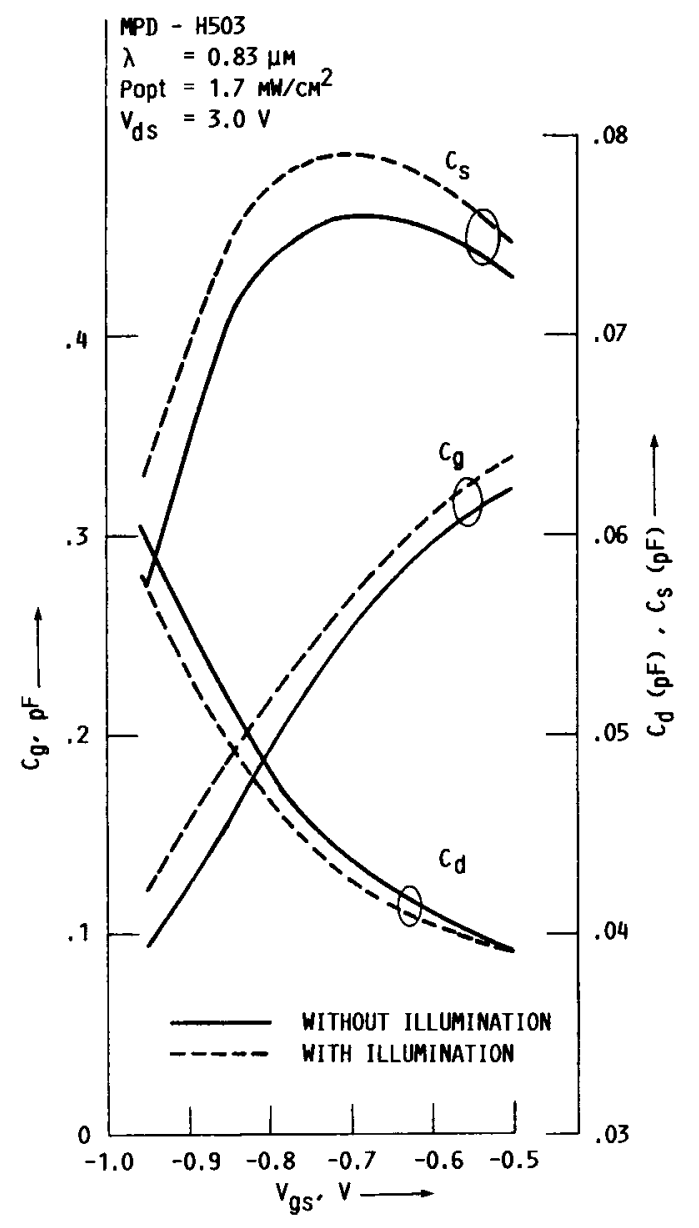

FIGURE 7. - DE-EMBEDED GATE, SOURCE, AND GAIE TO DRAIN CAPACITANCES FROM THE MEASURED S-PARAMETES WITH AND WITHOUT OPTICAL ILLUMINATION FOR ALGAAS/GAAS HEMT. 


\section{ORIGINIAL PAGE IS OF. POOR QUALTYY}

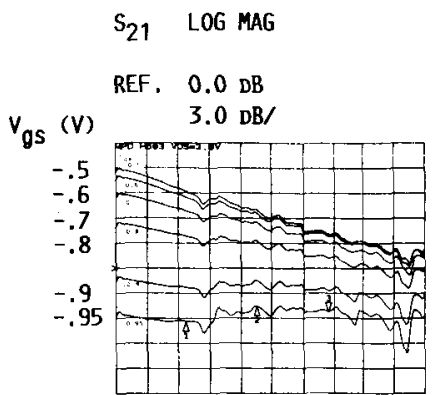

(A) $S_{21}$ MAGNITUDE WITHOUT OPTICAL ILLUMINATION.

$\mathrm{S}_{21}$ ANGLE

REF. $0.0^{\circ}$ $100.0^{\circ} /$

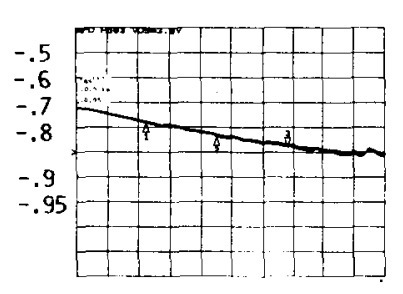

START $0.045 \mathrm{GHz}$ STOP $26.500 \mathrm{GHZ}$

(C) $S_{21}$ PHASE WITHOUT OPT ICAL ILLUMINATION.

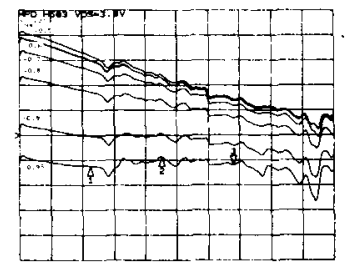

(B) $S_{21}$ MAGNITUDE WITH OPTICAL ILLUMINATION.

FIGURE 8. - MEASURED $S_{21}$ FOR ALGAAS/GAAS HEMT.

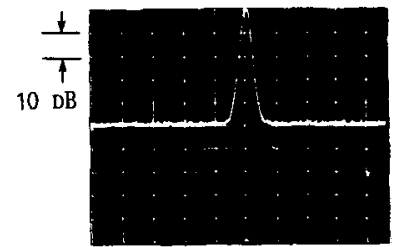

CENTER $6.000 \mathrm{GHz}$ SPAN $10.0 \mathrm{MHz}$

(A) DETECTED 6 GHZ SIGNAL.

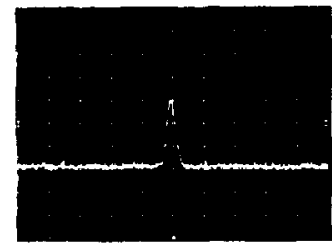

CENTER $3.000 \mathrm{GHZ}$ SPAN $10 \mathrm{MHZ}$

(B) $3 \mathrm{GHZ}$ IF SIGNAL.

FIGURE 9. 


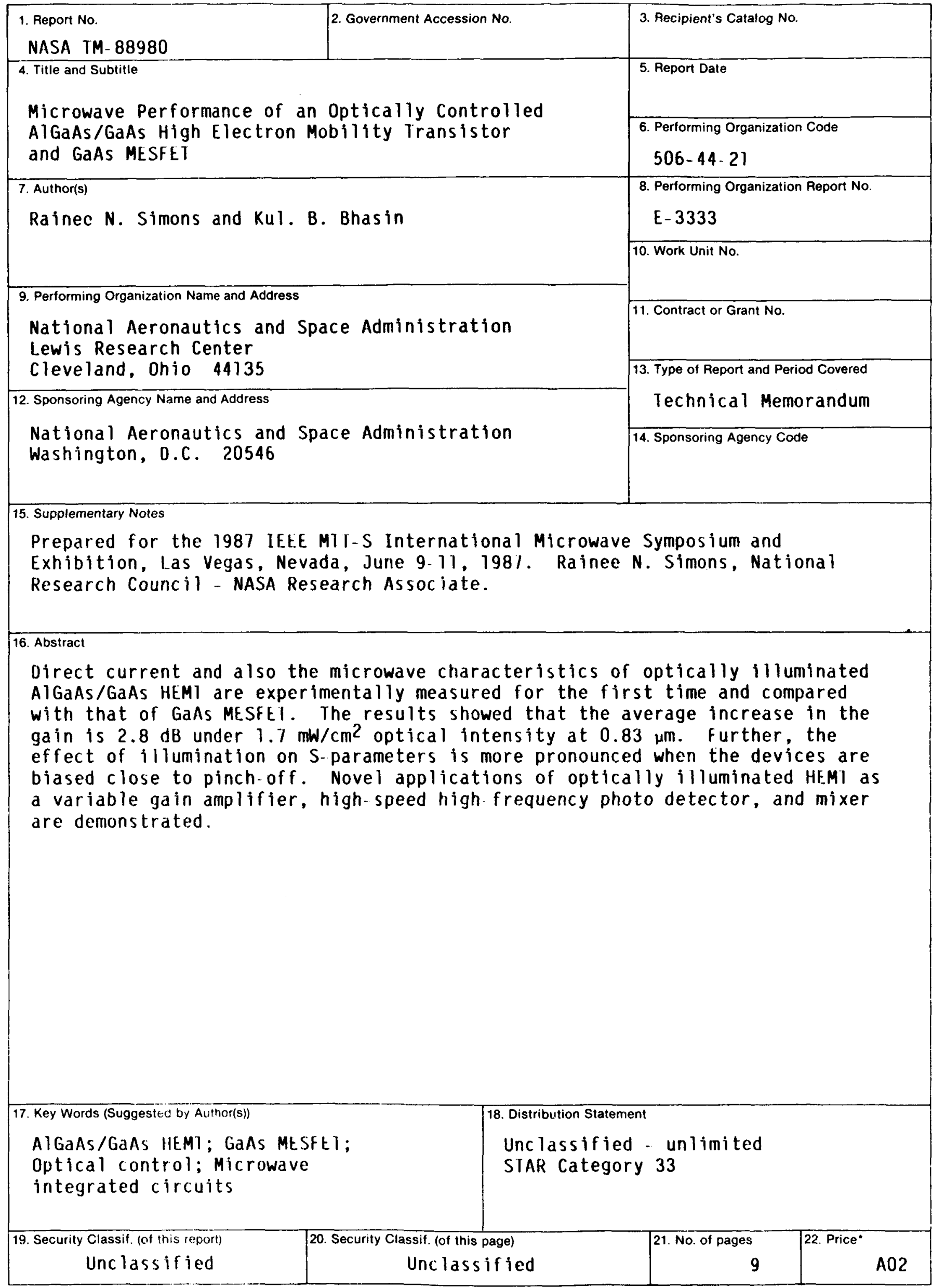

iof ale by the National Technical Information Service, Springfield, Virginia 22161 